\title{
Successful treatment of scleroderma renal crisis with enalapril
}

\author{
Stella R. Milsom and M. Gary Nicholls \\ Departments of Endocrinology and Cardiology, The Princess Margaret Hospital, Christchurch, New Zealand.
}

\begin{abstract}
Summary: A patient with scleroderma renal crisis is described. At presentation he had severe hypertension, deteriorating renal function, microangiopathic haemolytic anaemia, and elevated levels of renin, aldosterone and noradrenaline. Enalapril controlled blood pressure, stabilized renal function, lowered aldosterone and noradrenaline levels, and improved peripheral circulation. It appears that converting-enzyme inhibitors can favourably alter the outlook of this otherwise fatal disorder.
\end{abstract}

\section{Introduction}

Scleroderma renal crisis is characterized by abrupt onset or exacerbation of hypertension, hypertensive retinopathy, activation of the renin-angiotensin system, and rapid deterioration of renal function (Traub et al., 1983). Until the 1970s treatment was ineffective and death occurred within 1 year (Traub et al., 1983). Longevity increased with the advent of renal dialysis, vigorous anti-hypertensive therapy, or bilateral nephrectomy but the outlook remained bleak. Since 1979 , a number of reports described successful treatment of scleroderma renal crisis with the angiotensin converting-enzyme (ACE) inhibitor, captopril (Lopez-Ovejero et al., 1979; Thurm \& Alexander, 1984). We now report correction of biochemical and blood pressure abnormalities together with improvement in general clinical status and renal function with the second ACE inhibitory, enalapril, in a patient with scleroderma renal crisis.

\section{Case report}

A 45 year old white man was referred to the Hypertension Clinic. His blood pressure, previously normal, became elevated and was unresponsive to prazosin, and he developed nocturia and intense thirst. For 3 years he had suffered Raynaud's phenomenon, intermittent arthralgia and general malaise. Investigations, including renal function, had been normal. Examination revealed a miserable, unwell man, complaining of severe headache. Changes typical of scleroderma included acrocyanosis, calcinosis, telangiectasia, and thickening and tethering of skin on the hands. The

Correspondence: M.G. Nicholls, F.R.A.C.P., M.D., Department of Endocrinology, The Princess Margaret Hospital, Christchurch, New Zealand

Accepted: 15 May 1986 blood pressure was $240 / 140 \mathrm{mmHg}$ and he had a tachycardia (114 beats/minute). The fundi were free of haemorrhages, exudates and papilloedema. Laboratory testing showed microangiopathic haemolytic anaemia, elevated plasma levels of urea, creatinine, renin activity (PRA), noradrenaline and aldosterone (Figure 1). A diagnosis of scleroderma renal crisis was made and treatment started with enalapril.

Over the next 7 days while taking enalapril alone, his arterial presssure fell to around $140 / 90 \mathrm{mmHg}$, nocturia and headache disappeared, the peripheral circulation improved markedly, and normal vigour was restored. Since plasma urea and creatinine levels increased initially and urine sodium output was over $200 \mathrm{mmol} / 24 \mathrm{~h}$, his diet was supplemented with

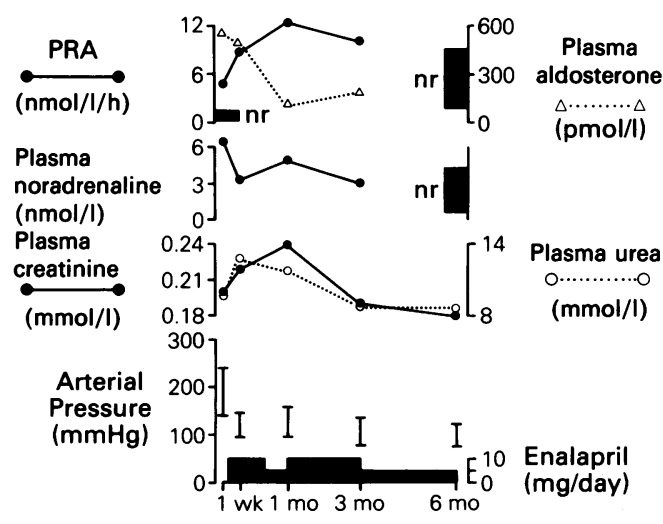

Figure 1 Hormones, renal function and arterial pressure in a patient with scleroderma renal crisis before and during treatment with enalapril. The normal range for plasma creatinine is $0.05-0.11 \mathrm{mmol} / 1$ and for plasma urea is $2.7-7.8 \mathrm{mmol} / 1$.

C The Fellowship of Postgraduate Medicine, 1986 
sodium for 6 days. Enalapril treatment resulted in a fall in plasma aldosterone and noradrenaline, and a rise in PRA (Figure 1). Subsequent follow-up showed normal blood pressure (average $130 / 85 \mathrm{mmHg}$ ), stable levels of urea and creatinine, normal concentrations of noradrenaline and aldosterone, and high PRA (Figure 1). A low dose of enalapril ( $5 \mathrm{mg} /$ day) was sufficient to maintain a normal blood pressure. Renal biopsy revealed typical changes of scleroderma on light microscopy.

\section{Discussion}

This patient had typical features of scleroderma renal crisis including activation of the renin-angiotensin system. In addition, plasma noradrenaline was high suggesting heightened activity of the sympathetic nervous system. Enalapril reduced angiotensin II formation as reflected by the fall in aldosterone and rise in PRA, while noradrenaline levels returned to

\section{References}

BARNETT, A.J. (1981). Medical treatment of hypertension and renal failure in scleroderma. Australian and New Zealand Journal of Medicine, 11, 411.

LOPEZ-OVEJERO, J.A., SAAL, S.D., D'ANGELO, W.A., CHEIGH, J.S., STENZEL, K.H. \& LARAGH, J.H. (1979). Reversal of vascular and renal crises of scleroderma by oral angiotensin-converting-enzyme blockade. New England Journal of Medicine, 300, 1417.

SMITH, C.D., SMITH, R.D. \& KORN, J.H. (1984). Hypertensive crisis in systematic sclerosis: treatment with the new oral angiotensin converting enzyme inhibitor MK 421 (en- normal. These changes were affected by a small dose $(5-10 \mathrm{mg} /$ day $)$ of the drug. As has been reported with $\frac{\mathbb{1}}{2}$ captopril (Lopez-Ovejero et al., 1979; Thurm \& Alexander, 1984), enalapril normalized blood pressure, $\stackrel{\leftarrow}{\Rightarrow}$ stabilized renal function, and improved peripheral $\stackrel{\vec{S}}{\vec{S}}$ circulation. This and another report (Smith et al., $\overline{0}$ 1984) suggests that inhibition of converting-enzyme, 흘 rather than treatment with any specific $\mathrm{ACE}$ inhibitor, $\overline{\bar{c}}$ can alter favourably the outlook in this otherwise fatal disorder. Although alternative forms of antihypertensive treatment have occasionally halted the progression of scleroderma renal crisis (Barnett, 1981), it $\vec{\circ}$ appears that ACE inhibitors are drugs of first choice in this disorder.

\section{Acknowledgements}

We thank Dr T.G. Yandle and the Endocrinology Tech- $\underset{\omega}{\omega}$ nicians for hormone measurements, and Mrs Natalie Purdue for secretarial help.

alapril) in captopril-intolerant patients. Arthritis and $\bar{\partial}$ Rheumatism, 27, 826.

THURM, R.H. \& ALEXANDER, J.C. (1984). Captopril treatment of scleroderma renal crisis. Archives of Intern Medicine, 144, 733.

TRAUB, Y.M., SHAPIRO, A.P., RODNAN, G.P., MEDSGER, T.A., MCDONALD, R.J. JR., STEEN, V.D., OSIAL, T.A. JR. \& TOLCHIN, S.F. (1983). Hypertension and renal failure (scleroderma renal crisis) in progressive systemic sclerosis. Medicine, 63, 335. 